\title{
Forms and practices of accountability in education
}

\section{Guri Skedsmo $^{1,2} \cdot$ Stephan Gerhard Huber ${ }^{3}$}

Published online: 19 August 2019

(C) Springer Nature B.V. 2019

Amid rising concerns in recent decades about the performance, equity, and efficiency of education systems, policy-makers worldwide have sought to reform educational governance. Key reform elements include standardized testing, teacher monitoring and evaluation, and accountability, often in combination with other features such as decentralization and market orientation (Verger et al. 2019). Researchers in different countries have explored accountability as phenomenon, concept, policy, and social practice within different systems of educational governance. In capturing this complexity, typologies of accountability defined and developed over time reflect changes in governing logics and political agendas in particular contexts. Here, we consider two views of accountability rooted in the US context and widely referred to in international studies of educational governance. Although developed at different times - and, in one case, in another domain - they remain relevant for understanding accountability practices in education today.

In 1987, Romzek and Dubnick published an analysis of factors that may have contributed to the accident in the year before involving the Challenger space shuttle, in which all seven crew members lost their lives. Identifying different systems or forms of accountability, Romzek and Dubnick proposed that multiple actors could be held to account for what happened, offering an alternative explanation that differed from the official account of the Rogers Commission (the Presidential Commission on the Space Shuttle Challenger Accident). Defining accountability as the management of diverse expectations generated within and outside the organization, they described alternative ways of managing these expectations in terms of bureaucratic, legal, professional, and political accountability. Within each of these systems, they identified different roles and

Guri Skedsmo

guri.skedsmo@phsz.ch

$\triangle$ Stephan Gerhard Huber

stephan.huber@phzg.ch

1 Institute for Research on Professions and Professional Learning, Schwyz University of Teacher Education, Goldau, Switzerland

2 Department of Teacher Education and School Research, University of Oslo, Oslo, Norway

3 Institute for the Management and Economics of Education, University of Teacher Education Zug, Zug, Switzerland 
relationships and related these to degrees of authority and control. A bureaucratic system manages expectations by means of a hierarchical arrangement, based on a supervisory relationship between "subordinate" and "superior." This is often combined with legal accountability where the subordinate - for instance, a school principal-is the "executor" of legal provisions while the superior is the lawmaker or legal overseer. The system of professional accountability system is characterized by deference to expertise, in which hierarchical relationships may change, depending on the strength of the arrangement and who is defined as the expert. Finally, political accountability promotes responsiveness to constituents as the basis for open and representative government. While the Rogers Commission focused on the failures of NASA's technological and management systems, Romzek and Dubnick (1987) concluded that the key factor was the misalignment of accountability mechanisms related to NASA's core tasks and technical responsibilities. If professional accountability had carried the same decision-making weight as hierarchical structures and political pressure, the engineers' recommendation not to launch would not have been challenged by managers. In other words, decision makers obeyed their superiors rather than listening to experts with specialized knowledge, reflecting how systems coordinated by hierarchical power can work against each other.

In her 2002 article examining the standards-based education reform movement in the USA, O'Day explores accountability mechanisms that seek to improve student learning by improving the functioning of the school organization, taking the school as the unit of analysis. Drawing on the work of researchers at the Consortium for Policy Research in Education (CPRE), she contrasts the outcomes-based bureaucratic approach of Chicago Public Schools with the combination of administrative and professional accountability in Baltimore City Schools. O’Day emphasizes the need for professional accountability, characterizing teaching as far too complex an activity to be governed by bureaucratic rules and routines. However, as professionalism is seen as a pervasive weakness of the US education system, she concludes that external incentives and administrative assistance are important elements of school governance. O'Day's approach to accountability acknowledges the potential positive dynamic between professional actors and administrative processes in enhancing educational quality. Elmore (2006) subsequently coined the term reciprocal accountability to capture the idea that principals can only be held accountable for school results if support is provided to help the school to improve. Accountability practices of the kind proposed by O'Day and Elmore are likely to be effective in systems characterized by trust in results, fair evaluation, and organizational learning capacity, in which various accountability mechanisms are aligned.

\section{Articles in this issue of EAEA, 3/2019}

In the first article, Levy, Brunner, Keller, and Fischbach report the findings of their methodological analysis of empirical research on value-added (VA) models of teacher evaluation in 26 countries. Of the 370 reviewed studies, two-thirds were conducted in the USA. The purpose of VA modeling is to operationalize teacher or school 
effectiveness by juxtaposing the actual academic achievement of students attending a given school or taught by a certain teacher against expected achievement for students sharing similar background characteristics. The authors note that VA models are often used for accountability purposes and to make high-stakes decisions although researchers disagree whether VA scores can be used in this way. Based on their analysis, they conclude that many studies of VA modeling lack transparency, rigor, and consistency, and they argue that violations of model assumptions and reporting of statistical parameters must be checked to ensure that results facilitate public and scientific scrutiny.

In the second article, Firestone and Donaldson review the research on teacher evaluation. Focusing on empirical Race to the Top studies published in the USA after 2009, they explore how US teachers employ the data produced by these evaluations and the conditions that facilitate or inhibit formative use of those data. Using a Datadriven Decision Making (DDDM) model, the authors develop a framework for using evaluation data that includes stages such as accessing information, determining its utility, having constructive conversations about the information, using the information to learn and influence instructional practice, and enhancing student learning. They conclude that the data use perspective is useful for understanding how teacher evaluation can improve instruction by informing teachers' collective learning processes. They identify data from observations of teaching practice as especially promising in this regard, providing a social context for processing and learning from the data. In contrast, test and growth score data seem to be a source of stress for teachers; as these data are often used for accountability purposes, learning is often constrained. In conclusion, the article highlights areas where more research is needed.

In the third article, Welsh, Graham, and Williams examine how teachers in the US state of Georgia perceive and respond to the threat of school takeover by state-run "turnaround districts," a school improvement strategy that accompanies test-based accountability (TBA). They report that several states have already established such districts for consistently low-performing schools, and other states are preparing to implement similar measures. Based on qualitative interviews with teachers working in schools and districts that are eligible for state takeover, they report major concerns regarding the sustainability of this school improvement strategy. They go on to identify a range of negative consequences associated with the increased pressure on these schools, such as teacher exit and loyalty strategies.

In the final article, Kardas reports a qualitative study of governing structures and processes in secondary schools in Turkey, where school governance is characterized by centralized control and bureaucratic accountability. In the hierarchical relationship between superiors in central and regional educational authorities and their subordinates in schools, the latter are responsible for compliance with rules and the legislation and must implement directives from their superiors, based on their formal authority within the education system. However, steps have been taken to introduce policies that will increase school autonomy by developing systems for information flow and incorporating schools' academic achievements in school governance. The analysis compares policy intentions as expressed in government documents with the perceptions of school leaders and teachers as reflected in the interview data. The results indicate that new 
governing trends outlined in policy documents have not yet been operationalized as performance expectations or assessment criteria. According to school personnel, legal and bureaucratic forms of accountability are still emphasized. However, central control of teacher supervision is changing as principals take on the role of school inspectors and educational authorities become more sensitive to parental complaints.

\section{Some reflections}

Several questions can be raised about accountability, hierarchy, and control based on the article by Levy, Brunner, Keller, and Fischbach, including the extent of education authorities' use of VA scores when making decisions with significant consequences for teachers and the extent to which research community as "experts" influence policy, performance management systems, and accountability practices.

The concerns raised by Welsh, Graham, and Williams in their study of teachers' responses to the threat of turnaround districts highlight the potential unintended negative consequences of increased accountability pressures in hierarchical governing systems. Echoing O'Day (2002), it seems questionable whether the complexity of teaching in such challenging school contexts can usefully be managed by increasing the pressure on schools and key actors.

While accountability pressures in the US context focus on student performance in the article by Welsh, Graham, and Williams, Kardas reports that school compliance with legal regulations is at the center of school governing in Turkey. Both cases illustrate how hierarchical relationships raise questions about the status and power of the teaching profession and how professional accountability and ethics may place student learning (beyond testing and regulations) at the heart of educational activities.

Firestone and Donaldson demonstrate how data can be used to improve teachers' instructional practices by informing collective learning processes, so enhancing professional accountability as outlined by O'Day. Data from teaching observations are found to be especially promising, aligning with previous empirical evidence that such data more accurately reflect teachers' actual practices and their pedagogical and didactical knowledge base (cf. Mausethagen et al. 2018; Sun et al. 2016). Additionally, this data use perspective potentially assigns more equal weight to professional accountability, at least in the context of local decision-making processes.

\section{References}

Elmore, R. (2006). Leadership as the practice of improvement. In B. Pont, D. Nusche, \& D. Hopkins (Eds.), Improving school leadership. Case studies on system Leadership (Vol. 2, pp. 37-67).

Mausethagen, S., Prøitz, T. S., \& Skedsmo, G. (2018). Teachers' use of knowledge sources in 'result meetings': thin data and thick data use. Teachers and Teaching: Theory and Practice, 43(6), 37-49. https://doi.org/10.1080/13540602.2017.1379986.

O'Day, J. (2002). Complexity, accountability, and school improvement. Harvard Eudcational Review, 72(3), 293-329. https://doi.org/10.17763/haer.72.3.021q742t8182h238.

Romzek, B. S., \& Dubnick, M. J. (1987). Accountability in the public sector: lessons from the challenger tragedy. Public Administration Review, 47(3), 227-238. 
Sun, J., Przybylski, R., \& Johnson, B. J. (2016). A review of research on teachers' use of student data: from the perspective of school leadership. Educational Assessment, Evaluation and Accountability, 28(1), 533. https://doi.org/10.1007/s11092-016-9238-9.

Verger, A., Fontdevila, C., \& Parcerisa, L. (2019). Reforming governance through policy instruments: how and to what extent standards, tests and accountability in education spread worldwide. Discourse: Studies in the Cultural Politics of Education., 40, 248-270. https://doi.org/10.1080/01596306.2019.1569882.

Publisher's note Springer Nature remains neutral with regard to jurisdictional claims in published maps and institutional affiliations. 